\title{
Periodic review sessions contribute to student learning across the disciplines in Pharmacology
}

\begin{abstract}
Orla P. Barry ${ }^{1}$, Eleanor O' Sullivan ${ }^{2}$, and Marian McCarthy ${ }^{3}$
Abstract: Background: The teaching of the discipline of pharmacology is in constant flux. In order to meet the challenges of teaching pharmacology effectively we investigated a new teaching and learning strategy. Aim: Our aim was to investigate whether structured periodic review sessions (RS) could improve teaching and learning for students in a multidisciplinary undergraduate pharmacology module. Methods: Following each lecture students were asked to identify topics of difficulty in pharmacology using the one minute paper classroom assessment technique (CAT). Three review sessions were then introduced based on the problematic issues identified by students. They completed a pre- and post-review session multiple choice question (MCQ) examination to gauge improvements in their learning. Feedback was obtained from students at the end of the module regarding the acceptability, advantages and limitations of the CATs and the review sessions. Results: There was active participation by students in all thirteen CATs $(71.15 \% \pm 1.2 \%)$, three review sessions $(78.3 \% \pm$ $1.6 \%)$ and the end of module (EOM) questionnaire (81\%). A significant increase in student learning across all disciplines was observed in all three review sessions (**, $^{*}<0.01 ; * * *, p<0.001$ and ${ }^{* *}, p<0.01$ for review sessions $1-3$ respectively). The majority of students (99\%) expressed the opinion that the review sessions enhanced their learning of pharmacology. A limitation expressed by some students was the necessity to complete multiple CATs to support each of the three review sessions. Conclusion: Strategically structured student directed review sessions which are carefully designed and executed are an interesting and effective educational tool for improving and complementing student learning across the disciplines in pharmacology.
\end{abstract}

Keywords: Review sessions, classroom assessment technique, undergraduate pharmacology, questionnaire, multidisciplinary.

\section{Introduction}

The teaching of pharmacology has progressed substantially in recent years from a passive traditional didactic lecture format to a more interactive inclusive student/teacher model (Rogers, 2012; Sekhri, 2012; Zgheib et al., 2010). Of note, however, the delivery of pharmacological information in a conventional lecture is still required prior to engaging with new teaching and learning strategies (Fry et al., 1999; Rogers, 2012). In this way students can understand and familiarise themselves with the topic(s) before re-addressing, re-enforcing and supplementing key principles using alternate strategies. In addition they are a fact of reality given growing

\footnotetext{
${ }^{1}$ Department of Pharmacology and Therapeutics, Room 3.89 Western Gateway Building, Western Road, University College Cork,Cork, Ireland. o.barry@ucc.ie

${ }^{2}$ Oral Surgery, Cork University Dental School \& Hospital, Cork, Ireland. eleanor.osullivan@ucc.ie

${ }^{3}$ Teaching and Learning Centre, Ionad Bairre, University College Cork, Ireland. mmcarthy@ucc.ie
} 
student numbers as well as financial pressures (Brown \& Gamber, 2002). The error lies, however, when only didactic lectures are utilised which alone does not give the students the opportunity for deep learning (Bligh, 2000; Handelsman et al., 2004; McKeachie et al., 2006; Udovic et al., 2002).

The challenge to teach pharmacology effectively continues on a daily basis (Joshi \& Trivedi, 2010). The direct consequence of increased drug discovery has led to a continuous increase in the associated scientific information. Thus, it has become an almost impossible task to teach students all pharmacological facts relating to individual drugs (Achike \& Ogle, 2000). Only recently has significant consideration been given to the complexities of teaching and learning of pharmacology. Novel teaching techniques are now in vogue aimed at promoting a more integrated and efficient programme as well as improving the quality of teaching in the discipline and in turn student learning. These include wet practicals where students apply their knowledge in a practical context in the laboratory (Rogers, 2012; Sekhri, 2012), computer assisted learning which provides a dry laboratory experience (Coleman et al., 1995; Dewhurst and Norris, 2003), problem based learning (Gregson et al., 2010), small group learning (Morgan, 2003; Sekhri, 2012), team-based learning (Zgheib et al., 2010), use of structured role play (Morgan, 2003), case studies (Routledge 1999; Rogers, 2012), collaborative online learning, (Wiecha, 2003), audio visual aids (Banerjee et al., 2013), drug flash cards (Rogers, 2012) and electronic hospital libraries (Brewer \& Hiscock, 2001). Despite such interventions, however, many students continue to find it difficult to master core knowledge in pharmacology. They are often left memorizing unfamiliar terms, drug names and pathways with a very limited frame of reference.

To-date there is a paucity of studies investigating effective pharmacology teaching for multidisciplinary student learning within the same class (Darling-Hammond, 2008; Gardner \& Boix Mansilla, 1994; Kwan, 2002). Different topics and methodologies have been reviewed for teaching pharmacology to medical, dental, and nursing students (McBane \& Mesaros, 2010). However, pharmacological knowledge is essential not only for students who will be involved in clinical practice but also for those involved in the biological sciences (Kwan, 2002; Lymn \& Mostyn, 2010). The composition of the class chosen for this research project consists of chemistry, biochemistry, physiology, medical and visiting Erasmus (European Union student exchange programme) students. The last group (Erasmus students) have traditionally been part of the cohort of the class taking this module. Their backgrounds are closely aligned with other student groups in the class. While pharmacology is strictly related to physiology (and pathology), the challenge in teaching this class is to define a core of knowledge in pharmacology for each discipline according to the practice of each profession. Furthermore, the teaching of pharmacology to medical students differs from that to science students as medical students not only have to master core concepts in pharmacology but must also be able to relate this information to the relevant management of the underlying disease.

The purpose of this study was to explore a new teaching and learning strategy in pharmacology for students from multidisciplinary backgrounds. Previously the module consisted of didactic lectures with three associated laboratory practicals. We have now replaced some lectures with periodic RS which complement the traditional instructive lectures. Importantly, the teaching in the RS did not occur at the expense of students acquiring a lesser amount of essential knowledge in the lectures. The RS were designed to focus and highlight relevant pharmacological material for each discipline without providing excessive information. Individual student conducted CATs guided the design and activities of the RS. CATs are formative 
evaluation methods whose main aims are to permit assessment of student understanding and learning and to allow for timely feedback about the effectiveness of particular teaching techniques. Approximately fifty different CATs have been described to-date (Angelo, 1991a,b; 1998; Angelo \& Cross, 1993; Byon, 2005; Rouseff-Baker \& Holm, 2004) with limited qualitative and quantitative research assessing their value in improving student learning (Cottell \& Harwood, 1998; Simpson-Beck, 2011). Some CATs access student prior knowledge, recall and understanding (minute paper, muddiest point, background knowledge probe and memory matrix), while others assess student's skill set in analysis and critical thinking (pro-and-con grid, categorizing grid, defining features matrix and content, form and function outlines). Furthermore, CATs permit assessment of students' skills in synthesis and creative thinking (concept maps), problem solving (problem recognition tasks), application and performance (application cards) and student self-awareness as learners (autobiographical sketches). Although the various CATs differ in their complexity and the time necessary for their preparation, administration and final analysis, they can all be utilised to improve course content, teaching methodologies and ultimately student learning. It is important to be aware, however, that irrespective of the CAT employed as with all educational interventions, due consideration must be given to the different learning styles of the students from the different disciplines. The approach taken in our CATs and the RS may not appeal to each and every student given different learning preferences (Gardner, 1995, 1999). Thus, in an effort to accommodate different learning strategies we incorporated different strategies into our RS including visual and auditory techniques. In brief, we observed that the RS aided students' learning and deepened their understanding in pharmacology. They permitted students to evaluate, synthesise and apply their knowledge of pharmacology more readily (Bloom, 1956; Cronin Jones, 2003; Ebert-May et al., 1997; Litke, 1995). Thus, periodic RS are an interesting and cost-effective tool worth exploring for effective teaching and learning to a disparate group of undergraduate students studying pharmacology.

\section{Method}

\section{Participants}

Research was conducted with an undergraduate pharmacology class of eighty nine students, forty eight of whom were male (54\%). Students were from four different disciplines i.e. chemistry, biochemistry, physiology, medicine as well as visiting Erasmus students. All students had completed at least one pharmacology module prior to enrolling in this module (PT2101/PT3005). The module was taught in three distinct sections namely (i) inflammation and anti-inflammatory drugs, (ii) antimicrobial chemotherapy and (iii) cancer chemotherapy. Students were delivered didactic lectures (as was traditionally done within this module) but also engaged in CAT, MCQs and RS which were newly introduced for our research purposes.

\section{Design, conducting and analysis of student CATs}

(i) Design: Students were asked to complete a one minute paper (Angelo \& Cross, 1993) at the end of each lecture stating (i) two pharmacological aspects that they understood well in the lecture and (ii) two pharmacological aspects that they found difficult to understand in the lecture. Topics listed in the latter question provided the basis for the RS. (ii) Conducting: At the end of each fifty minute didactic lecture students were given sufficient time to complete a CAT (this 
normally takes longer than one minute so students can process the lecture material and provide a response (Stead, 2012)). CATs are an invaluable learning tool not only for students but for the teacher as well. The advantages and disadvantages of the one minute paper have recently been reviewed (Stead, 2012), (iii) Analysis: CATs from all participating students were carefully read to ascertain the areas of student difficulties as well as ease in the preceding lecture. CATs were pooled from the first four lectures for RS1, the next four lectures for RS2 and the remaining five lectures for RS3. Topics of difficulty were entered into an excel sheet and formed the basis for each of the three subsequent RS. Each RS was based on six pharmacological topics most frequently identified as difficult by students.

\section{Description of the three Review Sessions}

RS1 and RS2 were conducted after a block of four lectures each covering inflammation and antimicrobial chemotherapy respectively. RS3 occurred following the remaining five lectures in the module covering cancer chemotherapy.

\section{Design and conducting of Review Sessions including MCQ examinations}

(i) Review topics: Six topics of difficulty identified most frequently by students formed the basis of the material to be re-addressed in the RS as well as the pre- and post-review MCQ questions. A single MCQ topic was assigned to each of the six problematic areas with five different questions of format T/F/D (true/false/don't know) associated with the topic. (ii) Format of the RS: Students completed the MCQ questions (6 topics x $5 \mathrm{~T} / \mathrm{F} / \mathrm{D}$ MCQ questions $=30$ questions in total) in the first fifteen minutes. The next thirty minutes was devoted to revisiting the six problematic areas identified by students in their CATs. The review time was used to reinforce the important and fundamental aspects of the six different pharmacological topics using an interactive teacher/student powerpoint presentation. The remaining fifteen minutes was allocated to the students re-sitting the same MCQ questions presented in the pre-review MCQ. Both pre- and post-review MCQs were printed on different colored paper and stapled together to allow analysis of student learning from individual students, while maintaining student anonymity. All MCQs were conducted anonymously except through identification of student discipline.

\section{Strategies to design the Review Sessions and MCQs}

Key challenges in designing and conducting the RS (as well as teaching the module in general) was to keep to the forefront the knowledge that the student group was diverse and from different disciplines. Thus, different criteria were adhered to in designing the MCQ examination questions (which did not differ in the pre- and post-review MCQ examination) as well as how the material identified by students was to be re-visited during the RS. Four different strategies were employed: (i) relevant; questions were designed and material was reviewed at an appropriate level to reflect the backgrounds, needs and diversity of students. All material was closely aligned with learning outcomes of the module; (ii) realistic; the level of pharmacology that the students required at this point in their training was taken into account (iii) engaging; both MCQ questions and material reviewed incorporated a mix of straight forward knowledge based enquiry as well as more challenging aspects of pharmacology (Bloom's Taxonomy, 1956) and (iv) instructional; 
the questions and material readdressed helped to inform and assess students' core and applied pharmacological knowledge.

\section{Analysis of pre- and post-review MCQ results}

Each participating student (identified by discipline only) submitted a pre- and postreview MCQ sheet for analysis, totalling sixty answers per student per RS. The correct answers to the thirty MCQ questions were firstly entered into an excel sheet, followed by student T/F/D answers to the pre- and post-review MCQs. A plus one value was assigned to each correct answer and a zero value to an incorrect answer or an unanswered question. Both the pre- and post-review MCQ results were analysed for each student. Lastly, the change in each student answer for all thirty MCQ questions was calculated between the pre- and post-review answers as follows; a value of zero was assigned to no change to a correct or incorrect answer, plus one for an incorrect to a correct answer and minus one for a correct to an incorrect answer.

\section{Questionnaire}

The written questionnaire is a powerful tool in research (Oppenheim, 1992, Wellington, 2000). An EOM questionnaire was designed to assess student feedback on teaching, learning and assessment methods in the RS. Students from all five disciplines completed the questionnaire in the last fifteen minutes of a two hour tutorial. The first half of the questionnaire consisted of seven statements with students indicating whether they strongly agreed (SA), agreed (A), neutral $(\mathrm{N})$, disagreed (D) or strongly disagreed (SA) with each of the statements. This part of the questionnaire was designed to determine quantitative data on student views of the RS as an unorthodox teaching, learning and assessment tool. The second half of the questionnaire invited qualitative comments from students on their experiences of the RS in an effort to identify advantages and disadvantages of this novel technique. Similar to the student CATs and pre- and post-review MCQ submission, the questionnaire was anonymous except for identification of the student discipline.

\section{Statistical Analysis}

Results are expressed as mean \pm S.E. Statistical comparisons were made by using analysis of variance with subsequent application of Student's $t$ test, as appropriate. GraphPad InStat 3 software was used for statistical analysis also.

\section{Ethical approval}

All students provided their signature at the commencement of the module indicating their willingness to participate in the different teaching, learning and assessment aspects of the RS. 


\section{Results}

\section{CAT participation and analysis}

All students present actively participated in the CATs following each lecture. Mean total class participation for all thirteen CATs was $71.15 \% \pm 1.2 \%$. Interestingly there was no statistically significant difference in student attendance and participation (there was 100\% correlation) in all thirteen CATs despite frequent EOM examinations in other subjects towards the end of the teaching period (data not shown).

The most frequently identified areas of difficulty outlined by students in their CATs can be summarized as follows; (i) new terminology, (ii) cellular pathways, (iii) drug pharmacodynamics i.e. the mechanism of action of drugs, (iv) drug inducers and inhibitors, (v) cell cycle control and (vi) multi-drug resistance. More specifically students outlined their misunderstandings and knowledge gaps relating to pro- and anti-inflammatory pathways including the arachidonic acid pathway, the peroxisome proliferator-activated receptor and the hypothalamic pituitary adrenal axis (Table 1). Clarification of drug pharmacodynamics was outlined in student CATs across all thirteen lectures (Table 1). A gap in their knowledge regarding drug inducers and inhibitors related to the pharmacology of the cytochrome P450 family of microsomal enzymes (Table 1). Students also requested revision of cell cycle control in the context of cancer proliferation and apoptosis, anti-microbial resistance and anti-cancer multidrug resistance (Table 1).

The CATs aided teaching as well as student learning as the module progressed. Students expressed (in their EOM questionnaire) that they paid significantly more attention and concentrated for a longer period of time (more than the average twenty minutes, McBane \& Mesaros, 2010) in the lectures in order to be able to complete the CATs. As each CAT was performed following a single lecture they provided an opportunity to access the standard of teaching and student learning in real time. Timely analysis of the CATs offered a window of opportunity to correct some teaching aspects which may have required adjustments prior to the subsequent lecture.

\section{Review session teaching and student learning}

The purpose of the RS (designed and conducted as outlined in Methods) was to complement the teaching in the lectures and to aid student learning. A significant proportion of the class attended and participated in each review session $(78.8 \%, 80.9 \%$ and $75.3 \%$ for RS1, 2 and 3 respectively). The highest participation in all three RS was seen in the medical student group with a mean value of $86.7 \% \pm 2.7 \%$, the lowest observed in the physiology student group with $65.10 \pm 1.6 \%$. This is an interesting observation as the module is an elective special study module for medical students but a compulsory module for physiology students.

Teaching: In RS1 students were taught how to distil down the various pathways into their associated elements focusing on the sites that are specifically targeted with clinically available drugs. Teaching was initially centered on pathway umbrella terms with more specific terms being introduced afterwards (Table 2). Teaching (partly in RS1) and mainly in RS2 focused on drug classes rather than on multiple individual drugs. A key difficulty in teaching pharmacology is dealing with the sheer volume of drugs that are clinically available. Students find it extremely difficult to remember drug names, associate each drug with a particular drug class and to memorize and retain the pharmacological components of each 
Table 1

Student CAT analysis

\begin{tabular}{|c|c|c|}
\hline $\begin{array}{l}\text { Lecture } \\
\text { number }\end{array}$ & Analysis of student CATs & Six main areas of student difficulty \\
\hline $1-4$ & $\begin{array}{l}\text { Pro- and anti-inflammatory pathways } \\
\text { Cox-2 specific inhibitors } \\
\text { Paracetamol } \\
\text { Glucocorticoids }\end{array}$ & $\begin{array}{l}\text { (i) AA, (ii) PPAR, (iii) HPA } \\
\text { (iv) Mechanisms of drug specificity } \\
\text { (v) Mechanism of drug poisoning and treatment } \\
\text { (vi) Mechanisms of action }\end{array}$ \\
\hline $5-8$ & $\begin{array}{l}\text { Antibiotics } \\
\text { Drug inducers and inhibitors } \\
\text { Folate as a pharmacological tool } \\
\text { Anti-virals } \\
\text { Antifungals } \\
\text { Anti-malarials }\end{array}$ & $\begin{array}{l}\text { (i) } \beta \text {-lactam cell wall synthesis inhibitors } \\
\text { (ii) Cytochrome P450 family } \\
\text { (iii) Folate synthesis, metabolism and utilisation } \\
\text { (iv) Mechanism of action of acyclovir } \\
\text { (v) Mechanism of action of flucytosine } \\
\text { (vi) Mechanisms of anti-malarial drug resistance }\end{array}$ \\
\hline $9-12$ & $\begin{array}{l}\text { Cancer genetics } \\
\text { Anticancer drugs } \\
\text { Cancer proliferation and apoptosis } \\
\text { Drug resistance }\end{array}$ & $\begin{array}{l}\text { (i) Prot-oncogenes versus oncogenes } \\
\text { Mechanisms of action of (ii) topoisomerase } \\
\text { inhibitors, (iii) aromatase inhibitors, (iv) EDGF } \\
\text { inhibitors } \\
\text { (v) Cell cycle control } \\
\text { (vi) Cancer multi-drug resistan }\end{array}$ \\
\hline
\end{tabular}

All CATs were a one minute paper completed by students at the end of each lecture. Six main areas of student difficulties were identified from lectures 1-4 for RS 1, lectures 5-8 for RS2 and lectures 9-13 for RS 3. AA; arachidonic acid, PPAR; peroxisome proliferator-activated receptors, HPA; hypothalamic pituitary axis.

individual drug. Thus, we employed a teaching technique using prototypical drugs i.e. a standard or typical drug which is a lead agent in a drug class (family). These are common agents used in exam questions. Knowledge of essential pharmacological principles of prototype drugs will later permit students to apply this knowledge instantaneously to similar drugs within the same drug class. Armed with core information using the prototype approach provides an adequate learning basis and knowledge store for both non-clinical and clinical years ahead. Thus, teaching in RS2 focused on drug classes using prototypical drugs rather than individual drugs. Key drug information (using the prototype drug) including name, how it works and major side effects were taught. Application of core knowledge was reinforced as opposed to the expectation that students should simply memorize vast volumes of drug data (Table 2). Also in RS2 students were taught to recognize potential drug-drug interactions using the cytochrome P450 (Cyt P450) family of liver microsomal enzymes as examples (Table 2). Drug classes were identifying as either substrates, inducers or inhibitors of Cyt P450 members initially. Individual drugs falling outside these three categories were outlined. Finally in RS3 anti-cancer drug pharmacology was 
reinforced by dividing drug classes into older non-targeted drugs versus newer specific targeted drugs. Commonly observed side-effects depending on whether the drug was a new or old chemical was highlighted to students. Again teaching in the RS complemented rather added to the material delivered in the lectures. Targeted review of student focused topics allowed for pharmacology to be revised in a cohesive, clear and concise manner. Reinforcement and in some instances repetition of some pharmacological topics helped deepen student understanding.

Table 2

Teaching and learning in the three review sessions

\begin{tabular}{|l|l|l|}
\hline $\begin{array}{l}\text { Review session } \\
\text { number }\end{array}$ & Teaching & Student learning \\
\hline 1 & $\begin{array}{l}\text { Inflammatory pathway(s) steps and } \\
\text { terminology }\end{array}$ & $\begin{array}{l}\text { (i) Umbrella terms } \\
\text { (ii) Specific terms }\end{array}$ \\
\hline 2 & Key aspects of drug classes & $\begin{array}{l}\text { (i) Pharmacology of drug classes using } \\
\text { prototype drugs } \\
\text { (ii) Apply knowledge to clinically relevant } \\
\text { drugs } \\
\text { (iii) Typical drug combinations }\end{array}$ \\
\hline 3 & Drug-drug interactions & $\begin{array}{l}\text { (i) Cell cycle control } \\
\text { (ii) Anti-cancer drugs old versus new } \\
\text { (iii) Side effects } \\
\text { (iv) Multi-drug resistance }\end{array}$ \\
\hline
\end{tabular}

Teaching is student driven based on the various CATs. Teaching emphasis is placed on key pharmacological aspects. Students learn core knowledge initially followed by its application to applied pharmacology.

Learning: The focus of the RS was to aid student learning by giving students the opportunity to revise pharmacological material a few days after the original lecture material was delivered when information and knowledge was still recent. This offered the students an opportunity to correct any misconceptions in a timely manner. The student/teacher interactive style used for the RS, as opposed to a teacher led didactic lecture aided student learning. Students learned to focus initially on pathway umbrella terms and then to concentrate on specific terms (Table 2). They saw the importance of learning pharmacology using the drug class prototype model initially in order to be able to apply their knowledge afterwards to specific drugs (Table 2). Students also learned how to identify important drug-drug interactions, learned how cancer arises and how drugs can tackle this global health issue (Table 2).

It was extremely important during the RS to keep to the forefront the knowledge based requirements of the different student cohorts from various disciplines. Thus, careful strategic planning of the teaching of pharmacological drug aspects was necessary for it to be applicable to chemistry, biochemistry, physiology, medical and visiting Erasmus students. The teaching topics utilized during the RS are outlined in Table 3. These included teaching students the importance of chemical structures in predicting structure/activity relationships and how to interpret pharmacological data in terms of drug-target pharmacodynamics (chemistry students), application of biochemical pathways and molecular pharmacology to understanding how drugs work (biochemistry students), the close association between physiology/pathophysiology and pharmacology and how some common drugs relate to these processes (physiology students), clinical application of basic pharmacology and how the mechanisms of drug actions relate to the 
management of specific diseases (medical students) and focusing on core pharmacological aspects (Erasmus students). The structured RS permitted more discipline driven teaching of pharmacology that was not always possible in the lectures. This was mainly driven by the fact that more time could be devoted to individual discipline related topics. Topics requiring further revision or clarification were clearly outlined by students' CATs and so could be specifically targeted to individual disciplines. Also, a higher level of student/teacher interactive discussion created an environment of a questions and answer session specifically targeted to individual student disciplines and requirements.

Table 3

Teaching strategies employed per discipline in each of the three review sessions

\begin{tabular}{|l|l|}
\hline Individual disciplines & Topics to improve student learning \\
\hline Chemistry & Structure/activity relationships \\
\hline Biochemistry & Biochemical and molecular emphasis \\
\hline Physiology & Physiological and pathophysiological emphasis \\
\hline Medicine & Clinical emphasis using real-world clinical situations \\
\hline Erasmus & General pharmacology \\
\hline
\end{tabular}

Teaching in each of the three $R S$ was tailored where possible to each of the five different student disciplines in the class.

\section{MCQ examination}

The objectives of the three MCQ examinations were to test students' core as well as applied knowledge in (i) inflammation, (ii) anti-microbials and (iii) cancer. Analysis of individual student pre- and post-RS MCQs readily indicated whether or not there was an improvement in student learning. There was a significant increase in mean MCQ results between the pre- and post-RS MCQ examinations for each of the three RS (Figure 1). Greatest improvement in overall student performances was observed in RS2 ( $\mathrm{p}^{* * *<0.001)}$ with similar values observed in RS1 $\left(\mathrm{p}^{* *}<0.01\right)$ and RS3 $\left(\mathrm{p}^{* *}<0.01\right)$. A similar significant increase in student learning was observed for all five disciplines in RS1-3 (data not shown).

On closer analysis of the data, it was interesting to observe that there was a significant improvement in student learning in all areas reviewed in the three RS i.e. cellular pathways, pharmacodynamics (PD), cancer and multi-drug resistance (Figure 2). In fact, the data permitted identification of individual questions and thus pharmacological topics that students from the different disciplines demonstrated the largest as well as the smallest improvement in learning (data not shown). For instance understanding of pro- and anti-inflammatory pathways (in RS1, in particular peroxisome proliferator-activated receptors pathway) and their overall pharmacological regulation remained challenging for the physiology cohort within the class. This was not evident in the biochemistry group of students for example. This may be explained by the fact that biochemistry students may have a stronger background in a range of biological and biochemical pathways (within the human body) taught in different modules within their 
discipline. Moreover, the physiology group of students found understanding the genesis of cancer and its pharmacological control more difficult than all other groups. While

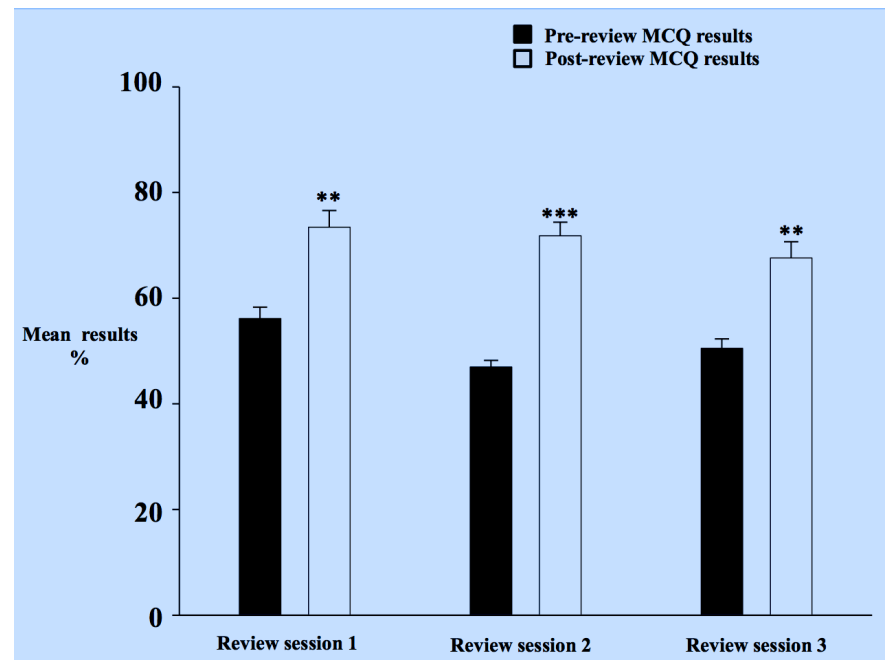

Figure 1. Students increase their mean MCQ examination results following review sessions. Mean class MCQ examination results in pre- and post-review MCQs carried out in review sessions 1-3. The results shown are mean \pm S.E. of the entire class performance. Significant (**, $p<0.01 ; * * *, p<0.001)$ changes from pre-review MCQ results.

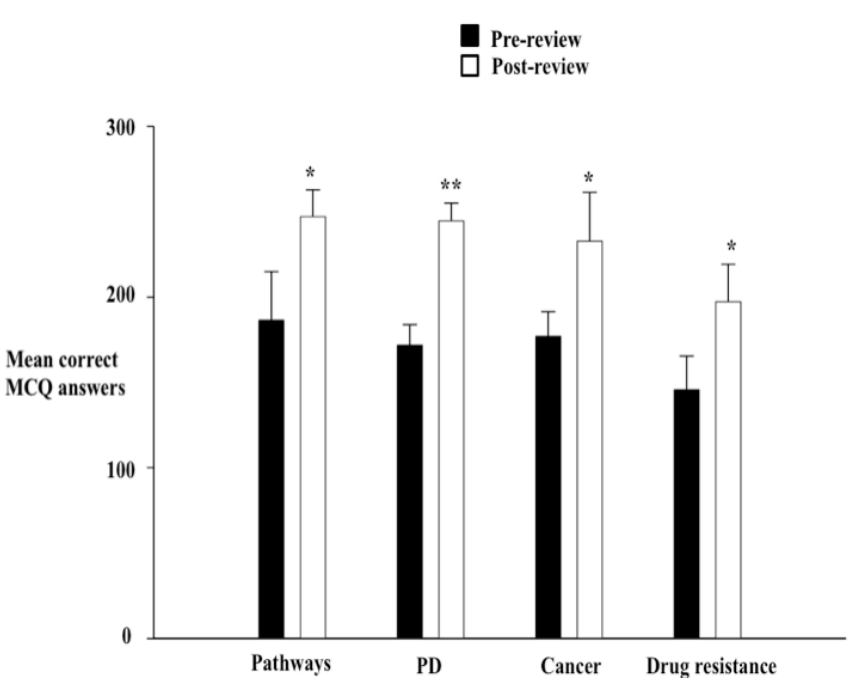

Figure 2. Students demonstrate improved learning in different pharmacological topics. The mean correct MCQ examination results in pre- and post-review MCQs for the entire class are shown for five independent pharmacological topics. The results shown are mean \pm S.E. of the entire class performance. Significant $\left({ }^{*}, p<0.05 ; * *, p<0.01 ;{ }^{* * *}, p<0.001\right)$ changes from prereview MCQ results. PD; pharmacodynamics.

analysis of the pre- and post-MCQs demonstrated a significant increase in their understanding in this topic the MCQ mean results for the physiology group were significantly lower $\left(\mathrm{p}^{* *}<0.01\right)$ than all other groups. It was also interesting to observe that all groups except the visiting 
Erasmus student group demonstrated a significant increase in their understanding of drug pharmacodyamics across a range of drug classes in all three RS (data not shown). This was not evident in the Erasmus group as they performed particularly well in this area of pharmacology in both their pre- and post-review MCQ examinations. This may be related to the fact that $80 \%$ of the visiting Erasmus student group was undertaking a pharmacy degree in their home country whereupon they may have previously undertaken a pharmacology module covering the pharmacodymanics of commonly used drugs. Lastly, of note it was the area of drug resistance in particular that proved most difficult for all student groups as evident from the lower mean correct MCQ answers in both the pre- and post-review MCQ (Figure 2). This was somewhat surprising as students are taught that in general drug resistance is related to drug pharmacodymanics. Once knowledge and understanding of a drug's mechanism of action is obtained, then by inference, so too is the mode of resistance associated with that drug. Overall, however, it was encouraging to see that there was a significant improvement in student learning in terms of core as well as applied pharmacological knowledge in all three RS (Figure 3).

Similar to the RS, the MCQ examinations provided a teaching and learning opportunity. In terms of teaching, there was an opportunity to ask students multiple targeted questions which is not possible in a traditional lecture. It also allowed for timely assessment of students' knowledge and understanding. From the student perspective the MCQs helped focus students' attention throughout the RS. They helped connect topics together which were specifically outlined by the students themselves and not the teacher. The MCQs provided opportunities for student self-assessment, a chance for the students to practice dealing with typical MCQs prior to the EOM MCQ examination and demonstrated to them the level of core and applied knowledge that was required in different pharmacological areas. Overall the MCQs enhanced student engagement and specifically guided student test taking logic.

\section{Questionnaire}

To investigate the effects of the various strategies used in this study student feedback was obtained using a written questionnaire covering various aspects of teaching, learning and assessment methods. Active participation was evident in all student disciplines (chemistry (95\%), biochemistry (100\%), physiology (57\%), medicine (84\%) and Erasmus $(67 \%)$ ). Of note least participation occurred in the physiology group which was previously observed in the RS $(65.10 \pm 1.6 \%)$. The first half of the questionnaire provided frequency rates for each statement in the survey. Frequencies were analysed per discipline (data not shown) as well as per total class student group (Table 4). Ninety three percent of the class "strongly agreed" and "agreed" with the first statement. In support of this statement one student commented (in the second half of the questionnaire) that "I concentrated more in the lectures knowing that I had to complete a CAT at the end outlining areas I understood well and areas of misunderstanding". The next statement "CATs became monotonous after a while" revealed the largest variation in student responses (Table 4). Interestingly, the medicine group (67\%) provided the highest "strongly agreed" and "agreed" responses with this statement. In contrast all other disciplines demonstrated lower percentages (chemistry: 28\%, biochemistry: 41\%, physiology: 58\% and Erasmus: 25\%) (data not shown). The positive response from students for the next two statements $(100 \%$ and $94 \%$ for statements 3 and 4 respectively) clearly indicated that the RS provided students with the opportunity to review lecture material which was directly focused on topics that students found difficult. Careful planning of the RS and associated MCQ examination questions proved fruitful 
as $94 \%$ of respondents indicated that the RS were closely aligned with topics students found difficult while 92\% indicated that the MCQ questions were at an appropriate level (statement 5, Table 4). Ninety percent of students welcomed active participation in their own assessment as a means to improving their overall leaning and understanding (statement 6, Table 4). Finally the majority of respondents (99\%) agreed that the RS enhanced their learning outlining the positive response of students to the RS as a tool for learning (Table 4).

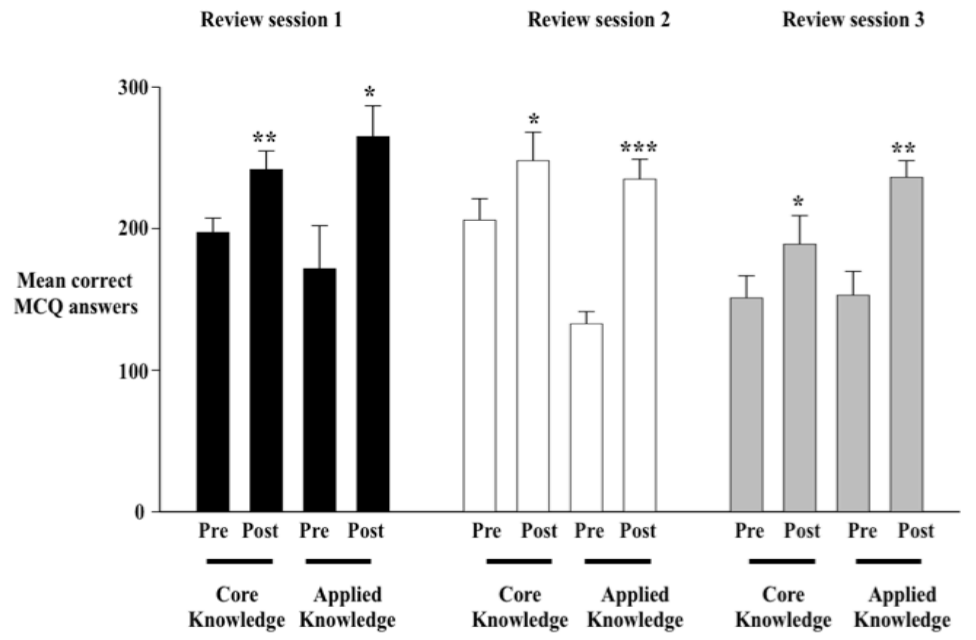

Figure 3. Students demonstrate improved learning in core as well as applied knowledge in pharmacology. The mean correct MCQ examination results in pre-and post-review MCQs for the entire class in review sessions 1-3. Results are shown for core as well as applied knowledge in each of the review sessions. The results shown are mean \pm S.E. of entire class performance. Significant ( $\left.{ }^{*}, p<0.05 ; * *, p<0.01 ; *^{* *}, p<0.001\right)$ changes from pre-review MCQ results.

On a personal level, the second half of the questionnaire provided important student responses indicating the positive and negative aspects of the RS as a novel teaching, learning and assessment technique. Analysis of the qualitative student feedback allowed for eight distinct categories to be devised. The positive aspects of the RS can be summarised as follows; (i) they assisted student understanding (90\%), (ii) they allowed for student self-assessment questions $(82 \%)$, (vi) they were conducted in a positive relaxed atmosphere $(23 \%)$, (vii) the topics covered were concise and student focused $(86 \%)$ and finally (viii) they provided structure to the pharmacological topics covered in the module (31\%).

Similarly, the negative student responses regarding the RS can be summarised into another eight distinct categories; (i) more time should be devoted to the RS (27\%), (ii) the absence of appropriate student feedback in terms of providing correct MCQ answers as well as individual student performances (6\%), (iii) the type of RS with the associated MCQ type examination as opposed to essay style or laboratory specific examinations (2\%), (iv) monotony of the CATs (47\%), (v) class size of the RS i.e the entire class instead of smaller individual groupings (4\%), (vi) use of similar lecture slides in the RS vs didactic lectures (35\%), (vii) large number of drug names (14\%) and finally (viii) omission of topics identified as difficult in the RS $(6 \%)$. It is important to note that while eight separate headings could be assigned to both the positive and negative student responses they were not equally weighted. While some of the negative responses can be readily addressed, others, however, are directly related to resource 
issues which are more difficult to tackle and could continue to have considerable controlling or restrictive implications. However, it was apparent that the extent of positivity highlighted with respect to the use of RS as a non-traditional teaching, learning and assessment method clearly overwhelmingly dominated the overall findings of the student questionnaire.

Table 4

Student responses to review session questionnaire statements

\begin{tabular}{|c|c|c|c|c|c|}
\hline \multicolumn{6}{|l|}{$\mathrm{N}=72(81 \%$ of the entire class $)$} \\
\hline & $\mathbf{S A}$ & $\mathbf{A}$ & $\mathbf{N}$ & D & SD \\
\hline The CATs were useful to outline difficult as well as easy topics & 37 & 30 & 4 & 1 & 0 \\
\hline CATs became monotonous after a while & 4 & 30 & 22 & 13 & 3 \\
\hline The review sessions were a good way of reviewing lecture material & 68 & 4 & 0 & 0 & 0 \\
\hline The review sessions were targeted to topics students found difficult & 57 & 11 & 4 & 0 & 0 \\
\hline $\begin{array}{l}\text { The MCQs in the pre- and post-review sessions were at an appropriate } \\
\text { level }\end{array}$ & 33 & 33 & 5 & 1 & 0 \\
\hline $\begin{array}{l}\text { Participation in your own assessment i.e. student CATs followed by } \\
\text { review sessions helped your learning and increased your understanding }\end{array}$ & 32 & 33 & 7 & 0 & 0 \\
\hline The review sessions in general enhanced your learning & 53 & 18 & 1 & 0 & 0 \\
\hline
\end{tabular}

Questionnaires were completed in-class in a relaxed and non-timed fashion. Students were asked to give their opinion on seven different statements by answering SA; strongly agree, A; agree, $N$; neutral; D; disagree, SD; strongly disagree.

\section{Discussion}

Pharmacology has long been recognized as a formal discipline in scientific medicine (Flexner, 1910). While there it holds its rightful place, it also seamlessly integrates into many interdisciplinary areas of basic and clinical sciences. In light of this fact it is not unusual to discover a number of distinct student groups from different disciplines in the one pharmacology class. For this particular study one of the key features that influenced the class choice was its multidisciplinary nature. While the module used in this study like all others in the discipline aims to teach the undergraduate student the principles of pharmacology along with the process of pharmacologic reasoning, the key goal of the intervention was to improve teaching and learning for multidisciplinary students. Chemistry students were taught to appreciate the structural diversity of pharmacological drugs, their chemical characteristics and applications. The biochemistry students were taught how drugs regulate various metabolic pathways and how important sequence data is to drug function. The physiology students were taught how drugs relate to physiological and pathophysiological processes in the human body and lastly, the medical students were taught the pharmacological management of selected major diseases. In contrast to the lectures the RS were student designed and targeted which encouraged more interactive student and teacher engagement. They were employed to continually engage students while keeping the information succinct and focusing on essential principles necessary for each discipline. 
One of the important findings of this study is that, despite the differences in student disciplines and backgrounds they succeeded in using the RS to their advantage and improving their understanding and knowledge of both core and applied pharmacological concepts. Student performances significantly improved following participation in the RS as evident from analysis of pre- versus post-review MCQ examination results for each individual student. This enhancement was both discipline- as well as topic-independent as each of the RS readdressed different areas of specialisation in pharmacology. However, overall mean correct MCQ examination results did vary somewhat between the various groups in all three RS. This is not surprising given the diverse pharmacological topics and concepts covered and examined in this module and the associated diversity of the five distinct student groups. In addition the vertical and horizontal integration of the different curricula within each discipline adds another layer of diversity within individual groups. Overall vigilant preparation of appropriate MCQ examination questions as well as how topics were strategically re-addressed was extremely important. While this was somewhat challenging proper design and implementation of the RS was essential for them to be utilised as an effective teaching, learning and assessment tool.

Student feedback demonstrated that the RS were appreciated as a welcome change to traditional didactic lectures as outlined by the following two student responses "I consider the $R S$ and their associated MCQ examinations very useful compared with endless lectures to better understand pharmacology" and "I really enjoyed the RS, an unusual change from regular lectures". They helped cement and reinforce essential topics in pharmacology in a relaxed and motivating environment conducive to learning. Student feedback provided important insight into the future design improvement of the RS. It is very encouraging that students suggested that the use of this technique would be beneficial in other modules both in related and unrelated disciplines. It was gratifying to observe the high level of attendance and engagement by students in all steps of the RS despite the absence of attainable marks which so often provides the only incentive for students' participation (Markham et al., 1998).

It is extremely important that recognition and appreciation of effective non-traditional teaching methods in pharmacology come from colleagues, students and institutions (Markham et al., 1998; Desai, 2009; Joshi \& Trivedi, 2010). Teachers of pharmacology are aware of nontraditional methods in teaching the discipline but lack of student and collegial motivation, lack of recognition by institutes, shortage of resources and the overall time involved in these processes lead some teachers to conclude that perhaps these alternative methods of teaching are a waste of time (Markham et al., 1998; Desai, 2009; Joshi \& Trivedi, 2010). More worryingly, a higher value can often times be accorded to conducting pharmacology research and consultancy activities rather than implementing and promoting effective teaching of pharmacology by focusing on teaching, learning and assessment. Thus, it is timely to not only seriously address the significance and value of researching teaching in pharmacology but to re-enforce its importance and equitable place in contributing to the effective functioning of the discipline.

In summation, we can conclude that RS are a successful and novel sole-instructor teaching and learning tool in pharmacology engaging large numbers of students from multidisciplinary backgrounds. This conclusion is based on comparing student performances, EOM student evaluations of the RS and student satisfaction with what they have learned and accomplished in the module. The success of our intervention is somewhat multifaceted. It lies in the active student participation in all elements of the RS which may be partially aligned to their novelty. The student-directed topics meant that the RS strategically focused on pharmacological elements directly related to each student discipline and thus readily pertinent. Overall the 
teaching and learning was different to didactic lectures in terms of being focused, relevant, interactive and relaxed. Some challenges along the way, however, cannot be ignored. Some students thought the CATs became monotonous after a period of time. The many hours devoted to the various steps associated with the RS: (i) analyzing each individual student CAT from multiple lectures, (ii) the design of the review topics, (iii) the design of appropriate MCQ examination questions, (iv) analyzing each individual student pre- and post-review MCQ examination results in each of the three RS and (v) interpretation of the resultant data. There is the omission of topics from the RS proffered by individuals but which could not be addressed due to time constraints. Finally, as outlined previously a significant proportion of the class completed the various CATs, attended each of the three RS and completed the EOM questionnaire. It must be noted, however, that $100 \%$ student attendance was never achieved in any of the outlined activities. In addition there was variation in the numbers of students attending from the different disciplines.

Despite the limitations outlined above it is our hope that this study will be a starting point for continuous experimentation and optimization of the use of novel periodic RS in the teaching of pharmacology to undergraduate students. In fact armed with the knowledge of our research limitations we are presently implementing an amended version of the research outlined in this report. One way of overcoming the limitation of not reaching full student attendance and participation is to reward students and have it aligned with their overall continuous assessment (CA). Thus, for each RS attended and post-review MCQ completed students are currently awarded a mark that is carried forward as part of their module overall CA. As a result of this new intervention we have now achieved $100 \%$ student attendance and participation. Another change currently being imposed is the extension of the RS to an hour and a half to encompass more topics outlined by individual students. It is our desire that other limitations will continue to be ironed out with future implementation of our research activities.

Lastly, the flexibility of our RS model will permit prospective researchers to not only replicate our process but importantly tailor it to their own needs and specifications. Our current approach may be modified and subsequently maintained through varying the one minute paper format and/or timing (Simpson-Beck, 2011; Stead, 2012) as well as the number of CATs utilised, completing CATs per student discipline group as opposed to individual student feedback, reducing the number of RS if necessary and implementing a more automated system for analysis of student feedback in general where appropriate. Thus, awareness of the associated limitations of the existing RS model and some potential ways of overcoming them will assist further in the effective implementation of our research activities. In addition future research should not only further test but also extend our findings to go beyond the student disciplines we have outlined in this study. Importantly our research activities were positively linked with increased teacher job satisfaction and teachers' self-efficacy (data not shown). This is despite the increased workload associated with our research activities (which may be reduced in the future) and the possibility of lack of recognition for accomplishments (Greenglass \& Burke, 2003; Klassen et al., 2010). However, the positive engagement by a high percentage of the students in all aspects of the RS, good teacher-pupil rapport and overall success in improving student learning were directly linked to achieving high levels of personal satisfaction from the process. These are important findings as overall job satisfaction can in turn influence students' motivation and achievement (Klassen et al., 2010; Skaalvik \& Skaalvik, 2007). Our study clearly holds implications for improving teaching and student learning. Implementing our existing activities or an abridged adaptation in 
Barry, O.P., O’Sullivan, E., \& McCarthy, M.

future studies might provide more nuanced understandings of its effectiveness beyond the discipline of pharmacology.

\section{Acknowledgements}

The authors would like to acknowledge the support and assistance of the science, medicine, and Erasmus visiting students who participated in our research.

\section{References}

Achike, F. I., \& Ogle, C. W. (2000). Information overload in the teaching of pharmacology. Journal of Clinical Pharmacology, 40(2), 177-183. doi: 10.1177/00912700022008838

Angelo, T. (1991a). Introduction and overview: From classroom assessment to classroom research. New Directions for Teaching and Learning , 46, 7-15. doi: 10.1002/tl.37219914603

Angelo T. (1991b). Ten easy pieces: Assessing higher learning in four dimensions. New Directions for Teaching and Learning , 46, 17-31. doi: 10.1002/tl.37219914604

Angelo T. (1998). Classroom assessment and research: An update on uses, approaches, and research findings. New Directions for Teaching and Learning, 75, 1-2. doi: 10.1002/t1.7500

Angelo, T. A., \& Cross, K. P. (1993). Classroom assessment techniques, $2^{\text {nd }}$ ed., San Francisco: Jossey-Bass.

Banerjee, I., Roy, B., Sathian, B., Pugazhandhi, B., Saha, A., \& Banerjee, I. (2013). Teaching aids in pharmacology teaching and learning methodology: A study from a medical college in Nepal. International Journal Interdisciplinary and Multidisciplinary Studies, 1(1), 1-7.

Bligh, D. A. (2000). What's the use of lectures? San Francisco: Jossey-Bass.

Bloom, B. S., Engelhart, M. D., Furst, E. J., Hill, W., \& Krathwohl, D. (1956). Taxonomy of educational objectives. The Cognative Domain. New York: McKay.

Brewer, G., \& Hiscock, D. (2001). Medical education and practice in the information age. Postgraduate Medical Journal, 77(909), 425-427. doi: 10.1136/pmj.77.909.425

Brown, W. A., \& Gamber, C. (2002). Cost containment in higher education - Issues and recommendations, ASHE-ERIC Higher Education Report. 28(5).

Byon, A. S. (2005). Classroom assessment tools and students' affective stances: KFL classroom settings. Language and Education, 19(3), 173-93. doi: 10.1080/0950070508668673 
Barry, O.P., O’Sullivan, E., \& McCarthy, M.

Coleman, I. P. L., Foster, R. W., Hollingsworth, M., Morgan, R., Sewell, K., \& Walker, J. (1995). Drug targets and transduction systems. British Journal of Pharmacology, 115, 159.

Cottell, P., \& Harwood E. (1998). Do classroom assessment techniques (CATs) improve student learning? New Directions for Teaching and Learning, 75, 37-46. doi: 10.1002/t1.7504

Cronin Jones, L. L. (2003). Are lectures a thing of the past? Journal of College Science Teaching, 32(7), 453-457.

Darling-Hammond, L. (Ed.). (2008). Powerful learning: What we know about teaching for understanding. San Francisco: Jossey-Bass.

Desai, M. (2009). Changing face of pharmacology practicals for medical undergraduates. Indian Journal of Pharmacology, 41(4), 151-152. doi: 10.4103/0253-7613.56062

Dewhurst, D. G., \& Norris T. A. M. (2003). Helping teachers to embed e-learning materials into undergraduate pharmacology courses. Bioscience Education, 1(1).

Ebert-May, D., Brewer, M., \& Allred, S. (1997). Innovation in large lectures-teaching for active learning. Bioscience, 47, 601-607. doi: 10.2307/1313166

Flexner, A. (1910). Medical education in the United States and Canada. A report to the Carnegie Foundation for the advancement of teaching. Bulletin 4. Boston: Updyke.

Fry, H., Ketteridge, S., \& Marshall, S. (1999). A handbook for teaching and learning in higher education: Enhancing academic practice. Philadelphia, PA: Kogan Page Publishers.

Gardner, H. (1995). Reflections on multiple intelligences myths and messages. Phi Delta Kappan, 77(3), 200-209.

Gardner, H. (1999). Intelligence reframed: Multiple intelligences for the $21^{\text {st }}$ Century. New York: Basic Books.

Gardner, H., \& Boix Mansilla, V. (1994). Teaching for understanding within and across the disciplines. Educational Leadership, 51, 14-18.

Gregson, K., Romito, L. M., \& Garetto, L. P. (2010). Students' attitudes toward integrating problem-based learning into a D.D.S. pharmacology curriculum. Journal of Dental Education, 74(5), 489-498.

Greenglass, E. R., \& Burke, R. J. (2003). Teacher stress: Occupational stress in the service proffessions. New York: Taylor \& Francis.

Handelsman, J., Ebert-May, D., Beichner, R., Bruns, P., Chang, A., DeHaan, R., Gentile, J., Lauffer, S., Stewart, J., Tilghman, S. M., \& Wood, W. B. (2004). Scientific teaching. Science, 304(5670), 521-522. doi: 10.1126/science.1096022 
Barry, O.P., O’Sullivan, E., \& McCarthy, M.

Joshi, A., \& Trivedi M. (2010). Innovations in pharmacology teaching. International Journal of Pharmaceutical and Biomedical Research, 1(2), 62-64.

Klassen, R. M., Usher, E. L., \& Bong, M. (2010). Teachers collective efficacy, job satisfaction and job stress in cross-cultural context. The Journal of Experimental Education, 78, 464-486. doi: 10.1080/00220970903292975

Kwan, C. Y. (2002). Problem-based learning and teaching of medical pharmacology. NaunynSchmiedebergs Archives in Pharmacology, 366, 10-17. doi: 10.1007/s00210-002-0561-y

Litke, R. A. (1995). Learning lessons from students: What they like most and least about large classes. Journal on Excellence in College Teaching, 6(2), 113-129.

Lymn, J. S., \& Mostyn, A. (2010). Audience response technology: Engaging and empowering non-medical prescribing students in pharmacology learning. BMC Medical Education, 10, 73-83. doi: 10.1186/1472-6920-10-73

Markham, T., Jones, S. J., Hughes, I., \& Sutcliffe, M. (1998). Survey of methods of teaching and learning in undergraduate pharmacology within UK higher education. Trends in Pharmacological Science, 19(7), 257-262 . doi: 10.1016/S0165-6147(98)01221-8

McBane, S., \& Mesaros, J. (2010). Teaching pharmacology in a physician assistant program. Journal of Physician Assisted Education, 21(3), 18-22.

McKeachie, W. J., Svinicki, M. D., \& Hofer, B. K. (2006). McKeachie's teaching tips: Strategies, research, and theory for college and university teachers. Boston: Houghton Mifflin.

Morgan, J. H. C. (2003). New approaches to training general practitioners. Postgraduate Medical Journal, 79(930), 187-188. doi: 10.1136/pmj.79.930.187

Oppenheim, A. N. (1992). Questionnaire design, interviewing and attitude measurement. (2 $2^{\text {nd }}$ ed.) London: St. Martin's Press.

Rogers, K. M. A. (2012). A feasibility study on the development and integration of a teaching aid for pharmacology. International Journal of Modern Education Forum, 1(2), 53-61.

Rouseff-Baker, F., \& Holm A. (2004). Engaging faculty and students in classroom assessment. New Directions for Community Colleges, 126, 29-42. doi: 10.1002/cc.152

Routledge, P. A. (1999). The inter-face between clinical and laboratory pharmacology. British Journal of Clinical Pharmacology, 47(6), 611-612.

Sekhri, K. (2012). Teaching methodologies in pharmacology. A survey of students' perceptions and experiences. Journal of Education and Ethics in Dentistry, 2(1), 40-44. doi: 10.4103/09747761.115150 
Barry, O.P., O’Sullivan, E., \& McCarthy, M.

Skaalvik, E. M., \& Skaalvik, S. (2007). Dimensions of teacher self-efficacy and relations with strain factors, perceived collective teacher efficacy, and teacher burnout. Journal of Educational Psychology, 99, 611-625. doi: 10.1037/0022-0663.99.3.611

Simpson-Beck, V. (2011). Assessing classroom assessment techniques. Active Learning in Higher Education, 12(2), 125-132. doi: 10.1177/1469787411402482

Stead, D. R. (2012). A review of the one minute paper. Active Learning in Higher Education, 6(2), 118-131. doi: 10.1177/1469787405054237

Udovic, D., Morris, D., Dickman, A., Postlethwait, J., \& Wetherwax, P. (2002). Workshop biology: Demonstrating the effectiveness of active learning in an introductory biology course. BioScience, 52(3), 272-281. doi: 10.1641/0006-3568(2002)052[0272:WBDTEO]2.0.CO;2

Wiecha, J. M. (2003). Collaborative online learning (COL): A new distance learning method. Essential Drugs Monitor, 33, 36.

Wellington, J. (2000). Educational research: Contemporary issues and practical approaches. London: Continuum.

Zgheib, N. K., Simaan, J. A., \& Sabra, R. (2010). Using team-based learning to teach pharmacology to second year medical students improves student performance. Medical Teaching, 32(2), 130-135. doi: 10.3109/01421590903548521 